\title{
The impact of caudally administrated tramadol on immune response and analgesic efficacy for pediatric patients: a comparative randomized clinical trial
}

\author{
${ }^{1}$ Department of Anesthesia, College of Medicine, Assiut University, ${ }^{2}$ Department of Pediatric, College of Medicine, Assiut University, \\ ${ }^{3}$ Department of Clinical Pathology, College of Medicine, Assiut University, ${ }^{4}$ Department of Critical Care and Emergency Nursing, \\ Faculty of Nursing, Assiut University, Assiut, Egypt \\ Jehan Ahmed Sayed', Sayed Kaoud Abd Elshafy', Emad Zareif Kamel', Mohamed Amir Fathy Riad², \\ Amal Ahmed Mahmoud ${ }^{3}$, and Ghada Shalaby Khalaf ${ }^{4}$
}

Background: Immune responses appear to be affected by anesthetics and analgesics. We investigated the effects of caudal tramadol on the postoperative immune response and pain management in pediatric patients.

\begin{abstract}
Methods: Sixty ASA-I pediatric patients aged 3-10 years undergoing lower abdominal surgery. Patients were randomly assigned either to a caudal bupivacaine (0.25\%) group (group B), or a group that received caudal tramadol $(1 \mathrm{mg} / \mathrm{kg}$ ) added to the bupivacaine (0.25\%) (group T). Both were diluted in a $0.9 \% \mathrm{NaCl}$ solution to a total volume of $1 \mathrm{ml} / \mathrm{kg}$. The systemic immune response was measured by collecting blood samples preoperatively, at the end of anesthesia, and at 24 and 72 hours postoperatively, and studied for interleukin IL-6, C-reactive proteins (CRP) cortisol levels, and leucocytes with its differential count. Postoperative pain was assessed along with sedation scales.
\end{abstract}

Results: Postoperative production of IL-6 was significantly higher in group B at the end of anesthesia, than at the $24^{\text {th }}$ hour, and at the $72^{\text {nd }}$ hour in group B and group T, respectively. The immune response showed leukocytosis with increased percentages of neutrophil and monocytes, and a decreased lymphocyte response rate within both groups with no significant differences between the groups. Cortisol and CRP were significantly higher in group B.

Conclusions: Adding tramadol to a caudal bupivacaine block can attenuate the pro-inflammatory cytokine response, Cortisol, and CRP in children undergoing lower abdominal surgery. (Korean J Pain 2018; 31: 206-14)

Key Words: Abdomen; Caudal anesthesia; C-reactive protein; Cytokine; Differential leukocyte count; Immune response; Interleukin 6; Leukocytes; Surgery; Pediatrics; Tramadol; Post-operative pain.

Received April 13, 2018. Revised June 5, 2018. Accepted June 7, 2018

Correspondence to: Sayed Kaoud Abd Elshafy

Kornish Al Ibrahimeya, Qesm Than Asyut, Assiut Governorate 71515 Egypt

Tel: 0020882413200, Fax:0020882413201, E-mail: sayed_k_72@yahoo.com

Equipment utilized in this study was provided by Assiut University Hospitals, Assiut, Egypt. We received no additional funding.

(a) This is an open-access article distributed under the terms of the Creative Commons Attribution Non-Commercial License (http:// creativecommons.org/licenses/by-nc/4.0/), which permits unrestricted non-commercial use, distribution, and reproduction in any medium, provided the original work is properly cited.

Copyright (C) The Korean Pain Society, 2018 


\section{INTRODUCTION}

Caudal anesthesia is one of the most commonly used regional anesthesia techniques for postoperative pain relief in children [1]. Prolongation of the duration and potency of analgesia by using this technique has been achieved by adding various opiates which, in turn, can affect the immune response [2-6]. It is well-known that postoperative immune response to surgery is influenced by a variety of factors, including age, surgery, anesthetics, and pain management, including age, surgery, anesthetics, and pain management $[7,8]$.

Opioids have been reported to suppress the immune system, whereas pain can depress the immune function through its direct effect upon the hypothalamic-pituitary-adrenal (HPA) system, and the suppression of natural killer cells [9]. Volk et al. have mentioned that epidural opioids used for better analgesia can modulate the postoperative immunity reaction [10]. It is already known that opioids as additives to local anesthetics for analgesia augmentation and prolongation aren't devoid of side effects [11], and in both animal and human studies, opioids can carry some deleterious effects on this aspect [12]. As opposed to morphine, tramadol could have the ability to increase natural killer cell activity and hence offer potential immune-protective effect $[13,14]$.

Opioids can be used to reduce surgical stress which, in turn, induces immune dysfunction, however perioperative immunosuppression should be minimized to facilitate recovery from surgery without complications. We have tried to investigate how caudal tramadol could modulate such a response in pediatric patients.

\section{MATERIALS AND METHODS}

The study was approved by the Local Research Ethics Committee of the College of Medicine of Assiut University (IRB000087400), and registered in ClinicalTrials.gov (NCTO2703415).

An informed parent's consent was obtained. Sixty children of American Society of Anesthesiologists (ASA) physical status I, aged 3-10 years were enrolled in this double-blind prospective, comparative clinical study. All participants underwent elective lower abdominal surgeries in the Children's Hospital of Assiut University. Patients were excluded if they had any coagulation disorder, allergy to local anesthetics, major malformations of the lower spine, or any cutaneous or subcutaneous lesion at the site of injection.

Children were randomly and equally assigned into one of two groups, group $\mathrm{B}$ (bupivacaine) or group $\mathrm{T}$ (bupivacaine with tramadol mixture). Randomization was achieved through a web-based randomizer (https://www. randomizer.org/). According to randomization, the anesthesia technician prepared the studied drug used for the caudal block under completely aseptic conditions in a solution of $1 \mathrm{ml} / \mathrm{kg}$ with a maximum total volume of $20 \mathrm{ml}$ of the studied medications, diluted in $0.9 \% \mathrm{NaCl}$. The prepared solution contained bupivacaine (0.25\%) in group B and bupivacaine $(0.25 \%)$ in addition to tramadol $(1 \mathrm{mg} / \mathrm{kg})$ in group $\mathrm{T}$. The maximum total dose obupivacaine was 2 $\mathrm{mg} / \mathrm{kg}$ in both groups.

Premedication was achieved by $0.5 \mathrm{mg} / \mathrm{kg}$ oral midazolam $45 \mathrm{~m}$ before induction of anesthesia. Standard monitoring included five leads of ECG, noninvasive blood pressure, temperature, pulse oximetry for oxygen saturation, exhaled end-tidal $\mathrm{CO} 2$, and muscle relaxation via a peripheral nerve stimulator.

Induction of anesthesia was done through a face mask using sevoflurane in oxygen, then a 22 -gauge intravenous catheter was inserted on the dorsum of the hand, and peripheral venous blood was sampled (for a preoperative sample). An intravenous fluid of dextrose $5 \%$ in normal Saline $0.9 \%(3-5 \mathrm{ml} / \mathrm{kg} / \mathrm{hr}$.) was administered; and tracheal intubation was facilitated with cisatracurium 0.1 $\mathrm{mg} / \mathrm{kg}$. After the securance of the endotracheal tube, the patient was placed in the lateral decubitus position (on the right side) with the hips and knees flexed at a right angle.

A consultant anesthesiologist performed the caudal block under complete aseptic conditions using the loss of resistance technique without guidance from ultrasonography. Anesthesia was maintained with a sevoflurane in oxygen/air mixture (1:1 ratio) and cisatracurium $0.05 \mathrm{mg} /$ $\mathrm{kg} / \mathrm{dose}$. The patient was placed in the lateral decubitus position (on the right side) with the hips and knees flexed at a right angle. At the end of the surgery, a peripheral venous blood sample was taken, and the neuromuscular block was antagonized by neostigmine $(50 \mathrm{mcg} / \mathrm{kg}$ ) with atropine $(20 \mathrm{mcg} / \mathrm{kg})$ before extubation. Then, patients were transferred to the post-anesthesia care unit (PACU). 


\section{Data collection}

The primary outcome is the implication of caudal tramadol upon postoperative interleukin 6 (IL-6) in pediatric patients (as a part of immune response) undergoing lower abdominal surgery.

The secondary outcomes included the pediatric observational FLACC (Face, Legs, Activity, Cry, Consolability scale) pain scale (Table 1), time to the first rescue analgesia, the sedation scale, hemodynamic variables, and any adverse effects during the first 24 hours after surgery.

\section{1) Systemic immune response}

The peripheral venous blood samples were collected at the four-time points (preoperative, at the end of anesthesia, as well as 24 and 72 hours after surgery), for IL-6 assesment. The differential white blood cell count (WBC), serum cortisol, and $\mathrm{C}$-reactive protein (CRP) were inspected, as well in the same blood samples. Interleukin6 concentration was measured from a plasma sample which was centrifuged immediately after separation and stored at $-70^{\circ} \mathrm{C}$ for not more than two months, and non-competitive ELISA technique (A vibionhuman-orgenum, Rev 4.10) was used. Differential neutrophil, lymphocyte, and monocyte counts were attained using an ABX Micros 60 OT cell counter (RAB180 CEN). Serum cortisol concentration was measured using a chemiluminescent microparticle immunoassay (ARCHITECT, United States: 1-877-4ABBOT). Serum high sensitive (CRP) level was measured using an Accu-bind sandwich ELISA kit (mono bind inc, USA. code3125-300).

\section{2) Clinical variables of postoperative analgesia}

servational FLACC pain scale [15], at $2^{\text {nd }}, 4^{\text {th }}, 8^{\text {th }}, 12^{\text {th }}$, and $24^{\text {th }}$ hours. Time to first analgesia request (duration of analgesia) was recorded. When patient's FLACC pain scale was $>4$, paracetamol in a dose of $15 \mathrm{mg} / \mathrm{kg}$ was administrated and recorded.

\section{3) Sedation scale}

It included $(0$ = eye opens spontaneously, 1 = eye opens in response to verbal stimulation, 2 = eye opens in response to physical stimulation, and $3=$ unarousable) was also measured along with pain.

\section{4) Hemodynamic variables}

Heart rate (HR), mean arterial blood pressure (MBP), and peripheral oxygen saturation $\left(\mathrm{SPO}_{2}\right)$ were recorded before the induction of anesthesia, every $5 \mathrm{~m}$ intra-operatively, every 30 minutes for 120 minutes after transfer to PACU, hourly for the first 12 hours, and every two hours for the next 12 hours.

\section{5) Side effects}

Side effects, e.g., vomiting, pruritus, respiratory depression, motor weakness (unable to stand unaided after three hours of recovery from anesthesia), and urinary retention, all were observed and recorded.

Intraoperative and postoperative follow-up of patients was done by an anesthetist who was kept blind to the randomization process. Parents were also kept blind to the randomization.

Postoperative pain was scaled through the pediatric ob-

Table 1. FLACC Score

\begin{tabular}{|c|c|c|c|}
\hline & Score 0 & Score 1 & Score 2 \\
\hline Face & $\begin{array}{l}\text { No particular expression or } \\
\text { smile }\end{array}$ & $\begin{array}{l}\text { Occasional grimace or frown, withdrawn, } \\
\text { uninterested }\end{array}$ & $\begin{array}{l}\text { Frequent to constant quivering chin, clenched } \\
\text { jaw }\end{array}$ \\
\hline Legs & Normal position or relaxed & Uneasy, restless, tense & Kicking, or legs drawn up \\
\hline Activity & $\begin{array}{l}\text { Lying quietly, normal } \\
\text { position, moves easily }\end{array}$ & $\begin{array}{l}\text { Squirming, shifting, back and forth, } \\
\text { tense }\end{array}$ & Arched, rigid or jerking \\
\hline Cry & No cry (awake or asleep) & Moans or whimpers, occasional complaint & Crying steadily, screams or sobs, frequent complaints \\
\hline Consolability & Content, relaxed & $\begin{array}{l}\text { Reassured by occasional touching, } \\
\text { hugging or being talked to, distractible }\end{array}$ & Difficult to console or comfort \\
\hline
\end{tabular}




\section{Statistical analysis}

A calculated sample size of 28 would have an $80 \%$ power to detect a difference of $20 \%$ in IL-6 changes after 24 hours postoperatively between groups (primary outcome variable) with a type I error of $\alpha=0.05$ using a confidence interval of $95 \%$. Thirty patients were enrolled in each group to compensate for any dropouts during the study. Statistical analysis was done using the computer program IBM, SPSS (Statistical Package for Social Sciences), Version 20. Normality of data distribution was evaluated with the Kolmogorov-Smirnov test. Data were expressed as mean, median, range, standard deviation (SD), numbers, or percentages as appropriate to the type of this data. Categorical variables were analyzed using the chi-square $\left(\chi^{2}\right)$ test. Continuous parametric variables were analyzed using an unpaired Student's t-test. Nominal and non-normally distributed variables were analyzed through a Mann-Whitney U test. A $P$ values $<0.05$ was considered statistically significant.

\section{RESULTS}

A total number of 60 patients were randomly enrolled in this study (Fig. 1). There were non-significant differences between groups regarding age, body weight, gender, and duration of anesthesia or type of surgery (Table 2).

Group T showed significantly lower IL-6 levels during

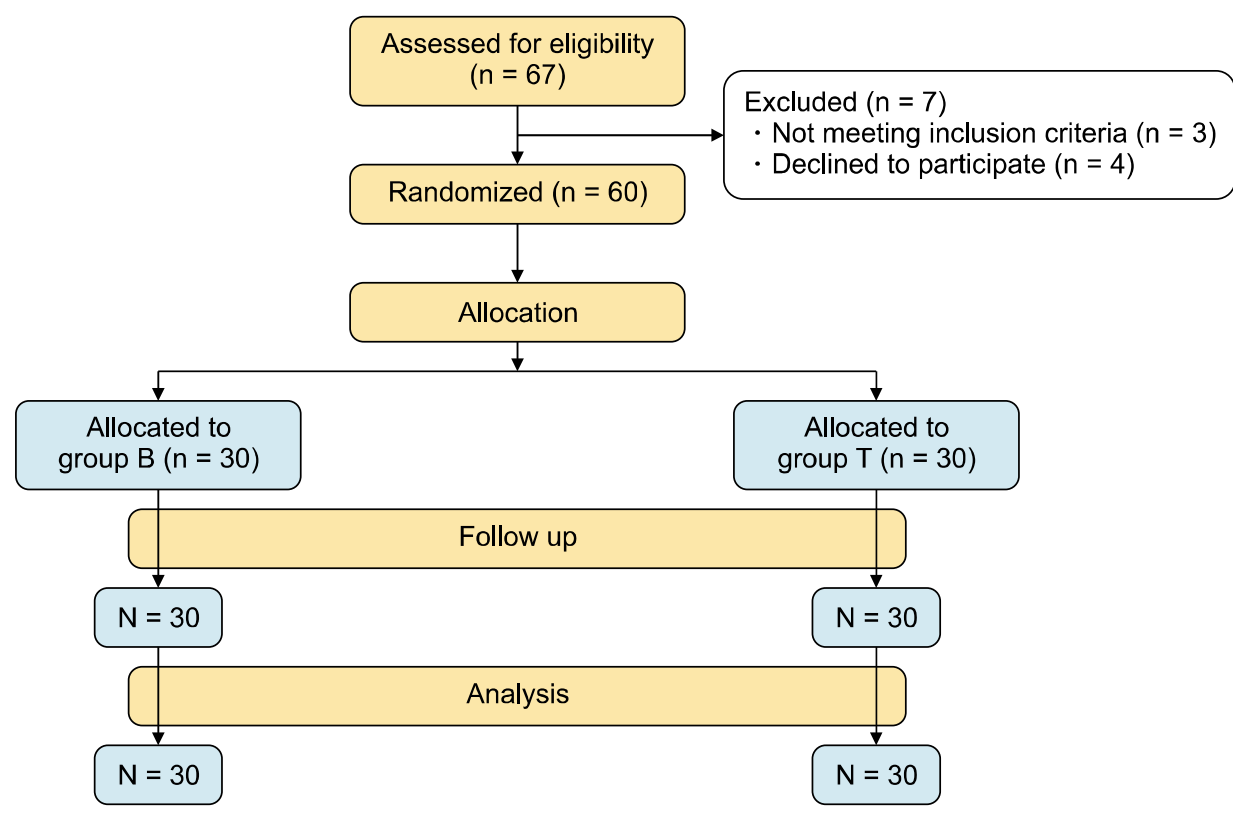

Fig. 1. CONSORT flow diagram

Table 2. Patient's Characteristics and Clinical Outcomes in the Two Studied Groups

\begin{tabular}{lccc}
\hline \multicolumn{1}{c}{ Variables } & Group B $(\mathrm{n}=30)$ & Group $\mathrm{T}(\mathrm{n}=30)$ & $P$ value \\
\hline Age (years) & $5.3 \pm 1.3$ & $5.75 \pm 1.3$ & 0.25 \\
Body weight (kg) & $18 \pm 7.9$ & $20.5 \pm 7.6$ & 0.29 \\
Gender (male/female) & $16 / 14$ & $19 / 11$ & 0.61 \\
Diagnosis & & & \\
Ectopic kidney & $14(46.70 \%)$ & $12(40.00 \%)$ & 0.74 \\
Stone kidney & $6(20.00 \%)$ & $6(30.00 \%)$ & \\
Cystolithotomy & $8(26.70 \%)$ & $3(10.00 \%)$ & 0.26 \\
Re-implantation of the ureter & $2(6.70 \%)$ & $95.5 \pm 9.7$ & 0.34 \\
Duration of anesthesia (min) & $92.5 \pm 9.6$ & $89.05 \pm 13.87$ & \\
Duration of operation (min) & $88.12 \pm 11.43$ &
\end{tabular}

Data are expressed as mean \pm SD, ratio, or percentage. Group B (Bupivacaine only), Group T (Bupivacaine with Tramadol). 
Table 3. Systemic Immune Response Items

\begin{tabular}{|c|c|c|c|}
\hline Variables & Group B $(n=30)$ & Group $T(n=30)$ & $P$ value \\
\hline \multicolumn{4}{|l|}{ Interleukin-6 (ngL $\left.{ }^{-1}\right)$} \\
\hline Preoperative & $26.2 \pm 5.6$ & $25.4 \pm 4.3$ & 0.55 \\
\hline At the end of anesthesia & $33.2 \pm 4.2$ & $27.6 \pm 4.5^{\star}$ & $<0.001$ * \\
\hline $24^{\text {th }}$ hour postoperatively & $35.6 \pm 4.3$ & $29.2 \pm 4.3^{*}$ & $<0.001 *$ \\
\hline $72^{\text {nd }}$ hour postoperatively & $25.5 \pm 4.6$ & $18.8 \pm 4.7^{*}$ & $<0.001^{*}$ \\
\hline \multicolumn{4}{|l|}{ Cortisol $\left(\mathrm{nmolL}^{-1}\right)$} \\
\hline Preoperative & $129 \pm 42.3$ & $119.3 \pm 22.9$ & 0.28 \\
\hline At the end of anesthesia & $199.5 \pm 64.9$ & $172.1 \pm 56.7$ & 0.09 \\
\hline $24^{\text {th }}$ hour postoperatively & $164.2 \pm 48.6$ & $142.9 \pm 31.2$ & $0.048 *$ \\
\hline $72^{\text {nd }}$ hour postoperatively & $140.7 \pm 27.8$ & $120 \pm 25$ & $<0.001^{*}$ \\
\hline \multicolumn{4}{|l|}{$\operatorname{CRP}\left(\mathrm{mgL}^{-1}\right)$} \\
\hline Preoperative & $4 \pm 2$ & $4.38 \pm 2.2$ & 0.67 \\
\hline At the end of anesthesia & $23.4 \pm 5$ & $18.90 \pm 3.2$ & $<0.001^{*}$ \\
\hline $24^{\text {th }}$ hour postoperatively & $17.4 \pm 5$ & $12.90 \pm 3.2$ & $<0.001 *$ \\
\hline $72^{\text {nd }}$ hour postoperatively & $12.9 \pm 5.5$ & $11.31 \pm 5.6$ & 0.26 \\
\hline
\end{tabular}

Data are expressed as mean \pm SD. Group B (Bupivacaine only), Group T (Bupivacaine with Tramadol). ${ }^{*} P$ value $<0.05$ was considered statistically significant.

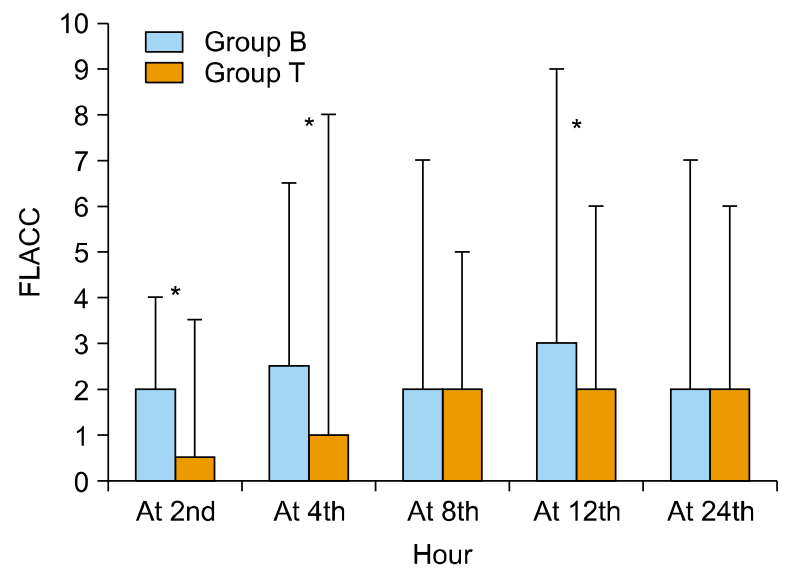

Fig. 2. Postoperative pain profile by FLACC (face, legs, activity, cry, and consolability) scale.

the whole postoperative study period than group B; however, levels of IL-6 were increased in both groups at the end of anesthesia and at the $24^{\text {th }}$ hour, then gradually decreased by the $72^{\text {nd }}$ hour, postoperatively. It was noticed that by the $72^{\text {nd }}$ postoperative hour, the IL-6 level in group $\mathrm{T}$ showed a much greater decrease below its corresponding preoperative basal value than its decrease in group B (Table 3).

On the other hand, serum cortisol levels were increased within both groups. These increases were significantly higher in group $\mathrm{B}$ than group $\mathrm{T}$ at the $24^{\text {th }}$ hour

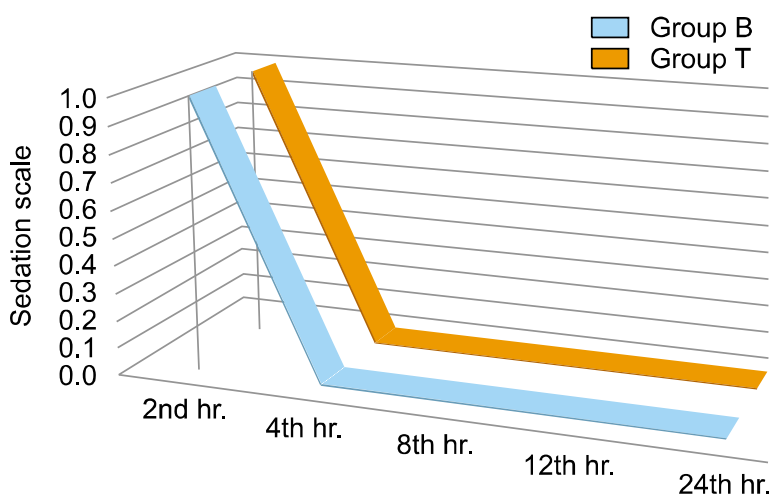

Fig. 3. Postoperative sedation scale.

$(P=0.048)$, and at the $72^{\text {nd }}$ hour $(P<0.001)$. CRP also markedly increased within the two groups in all postoperative readings, and was significantly higher in group B than group T $(P$ values $<0.001)$ by the end of anesthesia and at the $24^{\text {th }}$ hour (Table 3 ).

The blood picture also showed leukocytosis with increased percentages of neutrophil and monocytes at the end of anesthesia, and at the $24^{\text {th }}$ and $72^{\text {nd }}$ hours postoperatively, without a significant difference between the groups. Lymphocytes continued to decrease in both groups in the postoperative period, without significant differences in between (Table 4).

FLACC pain scales were lower in group $\mathrm{T}$, with sig- 
Table 4. Changes in Total and Differential Leucocytes in the Two Studied Groups at Different Times

\begin{tabular}{|c|c|c|c|}
\hline Variables & $\begin{array}{l}\text { Group B } \\
(n=30)\end{array}$ & $\begin{array}{l}\text { Group T } \\
(n=30)\end{array}$ & $P$ value \\
\hline \multicolumn{4}{|l|}{ Leucocytes $\left(x^{-9} L^{-1}\right)$} \\
\hline Preoperative & $5.74 \pm 1.12$ & $6.03 \pm 1.31$ & 0.83 \\
\hline At the end of anesthesia & $8.40 \pm 1.62$ & $9.23 \pm 2.20$ & 0.68 \\
\hline $24^{\text {th }}$ hour postoperatively & $7.23 \pm 2.11$ & $7.8 \pm 1.84$ & 0.91 \\
\hline $72^{\text {nd }}$ hour postoperatively & $6.24 \pm 2.21$ & $6.6 \pm 1.93$ & 0.73 \\
\hline \multicolumn{4}{|l|}{ Neutrophils (\%) } \\
\hline Preoperative & $42.72 \pm 2.30$ & $40.93 \pm 3.52$ & 0.48 \\
\hline At the end of anesthesia & $54.96 \pm 3.44$ & $52.81 \pm 3.25$ & 0.69 \\
\hline $24^{\text {th }}$ hour postoperatively & $58.91 \pm 3.61$ & $53.42 \pm 2.86$ & 0.35 \\
\hline $72^{\text {nd }}$ hour postoperatively & $59.32 \pm 4.40$ & $60.12 \pm 3.12$ & 0.86 \\
\hline \multicolumn{4}{|l|}{ Lymphocytes (\%) } \\
\hline Preoperative & $42.51 \pm 2.13$ & $41.37 \pm 3.12$ & 0.92 \\
\hline At the end of anesthesia & $33.67 \pm 2.41$ & $31.54 \pm 2.93$ & 0.73 \\
\hline $24^{\text {th }}$ hour postoperatively & $26.23 \pm 1.96$ & $24.23 \pm 2.51$ & 0.52 \\
\hline $72^{\text {nd }}$ hour postoperatively & $25.51 \pm 2.50$ & $27.50 \pm 2.66$ & 0.46 \\
\hline \multicolumn{4}{|l|}{ Monocytes (\%) } \\
\hline Preoperative & $5.41 \pm 0.42$ & $5.64 \pm 0.31$ & 0.81 \\
\hline At the end of anesthesia & $5.53 \pm 0.36$ & $5.64 \pm 0.63$ & 0.74 \\
\hline $24^{\text {th }}$ hour postoperatively & $6.62 \pm 0.52$ & $5.96 \pm 0.62$ & 0.49 \\
\hline $72^{\text {nd }}$ hour postoperatively & $6.56 \pm 0.36$ & $6.68 \pm 0.61$ & 0.79 \\
\hline
\end{tabular}

Data are expressed as mean \pm SD. Group B (Bupivacaine only), Group T (Bupivacaine with Tramadol). ${ }^{\star} P$ value $<0.05$ was considered statistically significant.

Table 5. Clinical Variables of Postoperative Analgesia

\begin{tabular}{lccc}
\hline & Group B $(\mathrm{n}=30)$ & Group T $(\mathrm{n}=30)$ & $P$ value \\
\hline Duration of analgesia (hours) & $7.16 \pm 1.88$ & $9.56 \pm 2.25$ & $<0.001^{*}$ \\
Total Paracetamol $(\mathrm{mg})$ & $729.66 \pm 278.36$ & $513 \pm 208.21$ & $0.001^{*}$ \\
Frequency of Paracetamol injection $(15 \mathrm{mg} / \mathrm{kg})$ & & & \\
Single time & $6(20 \%)$ & $15(50 \%)$ & $0.03^{*}$ \\
Two times & $15(50 \%)$ & $3(40 \%)$ & \\
Three times & $9(30 \%)$ & $3(10 \%)$ & \\
\hline
\end{tabular}

Data are expressed as number (percentage). Group B (Bupivacaine only), Group T (Bupivacaine with Tramadol). ${ }^{\star} P$ value $<0.05$ was considered statistically significant.

nificant differences at the $2^{\text {nd }}, 4^{\text {th }}$, and $12^{\text {th }}$ hours postoperatively in group $\mathrm{T}$ as compared to group $\mathrm{B}(P$ value $<$ $0.001, P$ value $=0.003$, and $P$ value $=0.003$ respectively , (Fig. 2).

Time to the first analgesia request was significantly longer in group T compared to group B ( $P$ value $<0.001$ ); subsequently, the dose of rescue analgesia was significantly higher in group $\mathrm{B}$ compared to group $\mathrm{T}(P$ value $=$ 0.001). The frequency of paracetamol injections was significantly higher in group B compared to group T (Table 5).
Postoperative sedation scales at different intervals were identical, with no significant difference among all patients within the two groups (Fig. 3).

None of the patients showed hypotension or bradycardia during the period of the study. No other complications (hematoma, postoperative agitation pruritus, respiratory depression, urinary retention, or motor weakness) were seen in either of the two groups. 


\section{DISCUSSION}

In this study, caudal epidural analgesia with tramadol and bupivacaine in children undergoing lower abdominal surgery has resulted in a modulation of surgery-induced immune response. Tramadol can influence the postoperative immune response as it has central analgesic properties with opioid- and non-opioid-like properties [16].

Both groups in our study showed leukocytosis with an increased neutrophil and monocyte percentage, but with non-significant differences. The lymphocyte response rate was slightly more depressed within the tramadol group, but with a non-significant difference. Our results are in agreement with the earlier reports which showed the ability of tramadol to decrease lymphocyte proliferative response after surgery $[17,18]$.

The insignificant difference between both groups could be explained by previous studies which found that tramadol has a potential immune-protective effect [13]. Sacerdote et al. mentioned that tramadol has less immune inhibitory action than morphine during the postoperative period in cancer patients [18]. In our study, there was an increase in the postoperative levels of IL-6, CRP (indicators of acute-phase and inflammatory mediator responses), and cortisol levels, and such increases were significantly less evident in tramadol patients. These results are in agreement with other studies which stated that tramadol could enhance secretion of IL-2 and Natural Killer cell activity $[13,19]$. These finding may also be related to the postoperative pain experienced by patients in each group.

Caudal tramadol in our study significantly provided more effective pain relief as noticed by the lower postoperative FLACC pain scales at the $2^{\text {nd }}, 4^{\text {th }}$, and $12^{\text {th }} \mathrm{h}$, and a prolonged duration of analgesia compared to the other group, as well as a subsequently lower dose of rescue analgesia.

Optimal and longer postoperative pain relief could be an explanation for lower levels of $\mathrm{IL}-6$ within the tramadol group, especially that these types of inflammatory mediators are correlated to the hyperalgesic states [20,21]. Thus, increased production of pro-inflammatory cytokines may contribute to more severe pain and vice versa [19]. In a comparative study done by Senel and his colleagues, caudal bupivacaine $0.25 \%(1 \mathrm{ml} / \mathrm{kg})$ with the addition of Tramadol $1.5 \mathrm{mg} / \mathrm{kg}$ has resulted in significantly longer postoperative analgesia duration of $13 \pm 2.2 \mathrm{~h}$, and these results agree with our finding [21].

An important goal of modern anesthesia is not only to provide balanced anesthesia but also to provide a good quality of pain relief. Ease of its performance and reliability make the caudal block the most commonly performed block in children [22]. The analgesic effect of a single injection of caudal bupivacaine often ends early within the postoperative period, as the drug has a limited duration of action [23].

Therefore, more than $60 \%$ of children undergoing lower abdominal surgery with the aid of a caudal block require further analgesia [24-26]. On the other hand, tramadol, when it was injected as an adjuvant to bupivacaine into the epidural space (caudal block), offered a longer duration of analgesia because of its well-known sustained release from the epidural fat, and other relatively poorly perfused tissues [27]. Güneş et al. [28] compared caudal versus intravenous tramadol (2 $\mathrm{mg} / \mathrm{kg}$ in both groups) as regards to its analgesia in 134 children (1-3 years old) undergoing Hypospadias repair. They concluded that caudal tramadol had provided better and longer analgesia than intravenous tramadol.

Our results were in contrast to the finding of Prosser and his colleagues [29], who demonstrated that caudally administered tramadol could act slowly, and its addition to bupivacaine did not offer an additional benefit, and hence there was no need for its injection into the caudal space. We think that our results are different because of the type of operations (our patients underwent lower abdominal surgeries, whereas the patients in Posser et al. underwent hypospadias repair). Also, our study's operative duration was longer, so that there was a sufficient time to allow the beneficial effect of tramadol to be seen. Moreover, our patients were of a different age group (an older age), and a different pain assessment tool was used. Murthy and his co-workers [30], studied the pharmacokinetics of tramadol and denoted that caudal tramadol's systemic absorption is slow, so that its therapeutic blood level may be too low to offer the desired effect.

We did not observe any serious adverse effects, and our minor complication rates were very low, and comparable in the two studied groups. These results are in agreement with studies which reported the safety of caudal tramadol $[28,31]$.

We did not evaluate the local effect of immune response change upon the wound healing due to poor com- 
munication with participants in our locality after discharge from the hospital. The caudal block was done under the loss of resistance technique without the guidance of ultrasonography. We did not measure tramadol serum levels at different time points. We recommend a further study of tramadol's immune system modulation upon wound healing, and the incidence of infection upon a larger number of participants.

We conclude that a caudal block adding tramadol (1 $\mathrm{mg} / \mathrm{kg}$ ) to bupivacaine significantly attenuated pro-inflammatory cytokine response to surgery and augmented the duration and intensity of postoperative analgesia in children undergoing lower abdominal surgery, with a greater effect than bupivacaine alone, with minor adverse actions.

\section{CONFLICT OF INTEREST}

The authors declare that there is no conflicts of interest and no source of funding.

\section{REFERENCES}

1. Khan S, Memon Ml. Comparison of caudal bupivacaine and bupivacaine-tramadol for postoperative analgesia in children with hypospadias repair. J Coll Physicians Surg Pak 2008; 18: $601-4$.

2. Stefano GB, Scharrer B, Smith EM, Hughes TK Jr, Magazine $H$, Bilfinger TV, et al. Opioid and opiate immunoregulatory processes. Crit Rev Immunol 1996; 16: 109-44.

3. Webster NR. Opioids and the immune system. $\mathrm{Br} J$ Anaesth 1998; 81: 835-6.

4. Carli F, Mayo N, Klubien K, Schricker T, Trudel J, Belliveau P. Epidural analgesia enhances functional exercise capacity and health-related quality of life after colonic surgery: results of a randomized trial. Anesthesiology 2002; 97: 540-9.

5. Hole A, Unsgaard G, Breivik $H$. Monocyte functions are depressed during and after surgery under general anaesthesia but not under epidural anaesthesia. Acta Anaesthesiol Scand 1982; 26: 301-7.

6. Hashimoto T, Hashimoto S, Hori Y, Nakagawa H, Hosokawa T. Epidural anaesthesia blocks changes in peripheral lymphocytes subpopulation during gastrectomy for stomach cancer. Acta Anaesthesiol Scand 1995; 39: 294-8.

7. Fan S, Zhong JL, Chen WX, Chen WL, Li QX, Wang YY, et al. Postoperative immune response and surgical stress in selective neck dissection: Comparison between endoscopically assisted dissection and open techniques in
cT1-2NO oral squamous cell carcinoma. J Craniomaxillofac Surg 2017; 45: 1112-6.

8. Shakhar G, Ben-Eliyahu S. Potential prophylactic measures against postoperative immunosuppression: could they reduce recurrence rates in oncological patients? Ann Surg Oncol 2003; 10: 972-92.

9. Raghavan S, Harvey AD, Humble SR. New opioid side effects and implications for long-term therapy. Trends Anaesth Crit Care 2011; 1: 18-21.

10. Volk T, Schenk M, Voigt K, Tohtz S, Putzier M, Kox WJ. Postoperative epidural anesthesia preserves lymphocyte, but not monocyte, immune function after major spine surgery. Anesth Analg 2004; 98: 1086-92.

11. Lönnqvist PA, Ivani G, Moriarty T. Use of caudal- epidural opioids in children: still state of the art or the beginning of the end? Paediatr Anaesth 2002; 12: 747-9.

12. Snyder GL, Greenberg S. Effect of anaesthetic technique and other perioperative factors on cancer recurrence. $\mathrm{Br} J$ Anaesth 2010; 105: 106-15.

13. Jensen KB, Lonsdorf TB, Schalling M, Kosek E, Ingvar M. Increased sensitivity to thermal pain following a single opiate dose is influenced by the COMT val (158)met polymorphism. PLoS One 2009; 4: e6016.

14. Niesters M, Proto PL, Aarts L, Sarton EY, Drewes AM, Dahan A. Tapentadol potentiates descending pain inhibition in chronic pain patients with diabetic polyneuropathy. $\mathrm{Br} J$ Anaesth 2014; 113: 148-56.

15. Merkel SI, Voepel-Lewis T, Shayevitz JR, Malviya S. The FLACC: a behavioral scale for scoring postoperative pain in young children. Pediatr Nurs 1997; 23: 293-7.

16. Liu YM, Zhu SM, Wang KR, Feng ZY, Chen QL. Effect of tramadol on immune responses and nociceptive thresholds in a rat model of incisional pain. J Zhejiang Univ Sci B 2008; 9: 895-902.

17. Zhou LW, Ding HL, Li MQ, Jin S, Wang XS, Ji LJ. Effect of tramadol on perioperative immune function in patients undergoing gastric cancer surgeries. Anesth Essays Res 2013; 7: 54-7.

18. Sacerdote P, Bianchi M, Gaspani L, Manfredi B, Maucione A, Terno $G$, et al. The effects of tramadol and morphine on immune responses and pain after surgery in cancer patients. Anesth Analg 2000; 90: 1411-4.

19. Liu Z, Gao F, Tian Y. Effects of morphine, fentanyl and tramadol on human immune response. J Huazhong Univ Sci Technolog Med Sci 2006; 26: 478-81.

20. Watkins LR, Maier SF, Goehler LE. Immune activation: the role of pro-inflammatory cytokines in inflammation, illness responses and pathological pain states. Pain 1995; 63: 289-302.

21. Senel AC, Akyol A, Dohman D, Solak M. Caudal bupivacaine-tramadol combination for postoperative analgesia in pediatric herniorrhaphy. Acta Anaesthesiol 
Scand 2001; 45: 786-9.

22. Prakash S, Tyagi R, Gogia AR, Singh R, Prakash S. Efficacy of three doses of tramadol with bupivacaine for caudal analgesia in paediatric inguinal herniotomy. $\mathrm{Br} J$ Anaesth 2006; 97: 385-8.

23. Lloyd-Thomas AR. Pain management in paediatric patients. $\mathrm{Br} J$ Anaesth 1990; 64: 85-104.

24. Wolf AR, Hughes D, Wade A, Mather SJ, Prys-Roberts C. Postoperative analgesia after paediatric orchidopexy: evaluation of a bupivacaine-morphine mixture. $\mathrm{Br} J$ Anaesth 1990; 64: 430-5.

25. de Beer DA, Thomas ML. Caudal additives in children-solutions or problems? $\mathrm{Br} J$ Anaesth 2003; 90: 487-98.

26. Kumar P, Rudra A, Pan AK, Acharya A. Caudal additives in pediatrics: a comparison among midazolam, ketamine, and neostigmine coadministered with bupivacaine. Anesth Analg 2005; 101: 69-73.

27. Girwalkar-Bagle A, Thatte W, Choudhari S. Preemptive caudal anaesthesia in children with bupivacaine- tramadol and levobupivacaine-tramadol: a randomized, double-blind, prospective study. Anaesth Pain Intensive Care 2015; 19: 13-9.

28. Güneş $Y$, Gündüz M, Unlügenç $H$, Ozalevli M, Ozcengiz D. Comparison of caudal vs intravenous tramadol administered either preoperatively or postoperatively for pain relief in boys. Paediatr Anaesth 2004; 14: 324-8.

29. Prosser DP, Davis A, Booker PD, Murray A. Caudal tramadol for postoperative analgesia in pediatric hypospadias surgery. $\mathrm{Br} J$ Anaesth 1997; 79: 293-6.

30. Murthy BV, Pandya KS, Booker PD, Murray A, Lintz W, Terlinden R. Pharmacokinetics of tramadol in children after i.v. or caudal epidural administration. $\mathrm{Br} J$ Anaesth 2000; 84: 346-9.

31. Solanki NM, Engineer SR, Jansari DB, Patel RJ. Comparison of caudal tramadol versus caudal tentanyl with bupivacaine for prolongation of postoperative analgesia in pediatric patients. Saudi J Anaesth 2016; 10: 154-60. 